\title{
BJGP OPEN
}

\section{The views of general practitioners about using sit-stand desks: An observational study}

\author{
Biddle, Gregory J H; Thomas, Nicholas; Edwardson, Charlotte L; Clemes, \\ Stacy A; Daley, Amanda J
}

DOI: https://doi.org/10.3399/BJGPO.2021.0203

To access the most recent version of this article, please click the DOI URL in the line above.

Received 21 October 2021

Revised 31 January 2022

Accepted 22 Febuary 2022

(C) 2022 The Author(s). This is an Open Access article distributed under the terms of the Creative Commons Attribution 4.0 License (http://creativecommons.org/licenses/by/4.0/). Published by BJGP Open. For editorial process and policies, see: https://bjgpopen.org/authors/bjgp-open-editorial-process-and-policies

When citing this article please include the DOI provided above.

\section{Author Accepted Manuscript}

This is an 'author accepted manuscript': a manuscript that has been accepted for publication in BJGP Open, but which has not yet undergone subediting, typesetting, or correction. Errors discovered and corrected during this process may materially alter the content of this manuscript, and the latest published version (the Version of Record) should be used in preference to any preceding versions 
The views of General Practitioners about using sit-stand desks: An observational study

Gregory J H Biddle, BSc, MSc, PhD, Research Associate, The Centre for Lifestyle Medicine and Behaviour, School of Sport, Exercise and Health Science, Loughborough University, Loughborough, LE11 3TU, UK. ORCID ID: 0000-0002-4394-0655

Nicholas Thomas, BSc, PhD, MB ChB, DCH, DFSRH, MRCGP, Royal College of General Practitioners Clinical Lead for Research, Royal College of General Practitioners, 30 Euston Road, London, NW1 2FB. ORCHID ID: 0000-0003-0460-6870

Charlotte L Edwardson, BSc, MSc, PhD, Associate Professor in Physical Activity, Sedentary Behaviour and Health, Diabetes Research Centre, University of Leicester, Leicester General Hospital, LE5 4PW, UK. ORCID ID: 0000-0001-6485-9330

Stacy A Clemes, BSc, PhD, Reader in Active Living \& Public Health, School of Sport, Exercise and Health Science, Loughborough University, Loughborough, LE11 3TU, UK. ORCID ID: 0000-0001-5612-5898

Amanda J. Daley, BSc, PhD, Professor of Behavioural Medicine, The Centre for Lifestyle Medicine and Behaviour, School of Sport, Exercise and Health Science, Loughborough University, Loughborough, LE11 3TU, UK. ORCID ID: 0000-0002-4866-8726 


\section{Abstract}

Background: Occupational sitting is associated with negative health outcomes. Sit-stand workstations have been shown to reduce sitting time in office workers, although there is no evidence on whether this change to practice would be acceptable to GPs.

Aim: To investigate GPs views about the use of sit-stand desks within general practice and the potential impact they may have on the nature and quality of consultations with adult patients.

Design and setting: Observational study involving GPs located across the United Kingdom.

Method: A online survey was emailed to members of the Royal College of General Practitioners and shared on social media. Only GPs working in the UK were eligible. The survey included questions on socio-demographics, GPs views about the use of sit-stand desks within their work, their levels of physical activity, total time spent sitting each day at work and time spent at work.

Results: 14,142 surveys were sent by RCGP to their members with 810 GPs responding with a further 33 responding via social media. $60.6 \%$ of GPs would like a sit-stand desks in their consultation room, while $19.2 \%$ already had one. Most GPs thought sit-stand desks could be used for telephone consultations (91.9\%) and administration tasks (92.3\%). There was less agreement about whether they could be used during face-to-face consultations ( $35 \%$ agreed), with the potential impact on the doctor-patient relationship raised as the primary concern.

Conclusion: The implementation of sit-stand desks had support from GPs, but their possible impact on the doctor-patient relationship should be considered in future research.

\section{Keywords}

General practice, general practitioners, sedentary behaviour, sit-stand desks 


\section{How this fits in}

The majority of GPs in the UK are likely to sit for long periods of their working day. There is no evidence about whether sit-stand desks could be used to reduce the time GPs spend sitting, leading to potential improvements in their health and wellbeing. Standing may also facilitate GPs conversations with patients about reducing their sitting time and increasing participation in physical activity. This study found that GPs would support the implementation of sit-stand desks within general practice, as long as consideration was given to the impact they may have on the doctor-patient relationship. 


\section{Introduction}

Sedentary behaviour in occupational settings has been associated with an increased risk of disease and conditions, including type 2 diabetes (1), musculoskeletal disorders (2), poor mental health $(3,4)$, and a lower quality of life (5). It has been well documented that office based employees spend a large amount of their working day sitting $(6,7)$, yet data on other occupations and settings have been limited. One example of this, is healthcare workers, particularly general practitioners (GPs), who are likely to be seated much of the day. High levels of sedentary behaviour are not only associated with poor health outcomes, but breaking up prolonged sitting with regular breaks of standing or light movement can improve markers of cardiometabolic health $(8-10)$, fatigue and vigour $(11,12)$, and can reduce musculoskeletal complaints (13).

Unlike other health care workers, GPs work can be centred around spending a lot of time in one place, the consultation room. This working environment has removed the need to move regularly. Therefore, it is important to explore ways in which GPs might be provided with opportunities to be less sedentary at work, potentially using sit-stand desks, which allow the user to either sit or stand at work. Not only might this approach enable GPs to become less sedentary, but the use of sit-stand desks may also prompt GPs to routinely have conversations with patients about reducing the time spent sitting and increasing physical activity levels to improve health. This is important because a large amount of the population typically sit for most of the day and are insufficiently physically active each day/week (14). Furthermore, evidence has indicated that GPs do not regularly discuss reducing sitting time and increasing participation in physical activity with patients (15).

Whilst standing by doctors to deliver health care is not new, for example as part of hospital ward rounds, these interactions are typically conducted with doctors standing and patients sitting, unlike GP consultations which are typically conducted with both the patient 
and GP sitting. Despite evidence from non-healthcare settings that has shown sit-stand desks to be effective at reducing the amount of time employees spend sitting, introducing these in GP consultations would be a large personal, cultural and environmental change for patients and GPs alike. There have been recent calls for sit-stand desks to be routinely implemented in general practice, however, to date there has been no evidence to support their use (16).

Before implementing sit-stand desks within general practice, it is important to consider the views of GPs about doing so, to consider how feasible and acceptable this change to practice may be, as well as understanding potential barriers to the successful implementation. This study aimed to investigate GPs views about the potential use of sitstand desks within general practice, their potential impact on the nature and quality of consultations with patients (adults), the impact that GPs perceive sit-stand desks would have on their productivity and their own health. We also aimed to explore any perceived potential barriers to successfully implementing sit-stand desks within general practice.

\section{Method}

Study design

This survey study was conducted in collaboration with the Royal College of General Practitioners (RCGP). Questionnaires were completed by participants (GPs) using Qualtrics, a specialist online survey software. The study was conducted between the 22 November and 11 December 2020. Once started, GP responders had a maximum of one month to complete the survey. All open surveys that were ongoing on 11 December 2020 were closed and data collect up until this date were recorded. Ethical approval was granted by Loughborough University Human Participants Sub-Committee (reference number 1498). All participants provided informed consent before completing the online survey. 
The RCGP sent the survey link to their members who had previously agreed and provided consent to be contacted about research and policy initiatives conducted by the College. Some GPs were also recruited via a link to the survey posted on social media. Only GPs working in the UK were eligible to take part. Medical students and retired GPs were excluded from the data analysis.

\section{Questionnaire themes}

The questionnaire contained five sections, two of which were optional (this was to maximise our responses for the primary objectives). Socio-demographic data, including age category, gender, ethnicity and job role, views about the use of sit-stand desks within general practice, and participation in physical activity (17) were completed first. These were then followed by optional questions about the number of hours worked and total time spent sitting at work each day, and items relating health and wellbeing, including height, weight, feelings of burnout (18), musculoskeletal health (19), and psychological wellbeing (20). GPs were only asked to reflect on using sit-stand desks, in face-to-face consultations, with adult patients able to stand. An open text box was also included to give GPs the opportunity to make additional comments they wished to make.

\section{Data analysis}

Data were analysed using IBM SPSS Statistics 27. Data were first analysed to describe the characteristic of the recruited sample of GPs. Descriptive statistics summarised GPs views of the use of sit-stand desks. Analysis of covariance (ANCOVA) was used to examine whether the views of GPs differed between age categories, gender, the number of sessions worked each week, adherence to physical activity guidelines and current use of a sitstand desk at work (adjusted for year of qualification as GP, job role, practice list size and ethnicity). The open text comments made by GPs were thematically coded. Data on health, wellbeing, physical activity and sedentary behaviour are reported elsewhere. 


\section{Results}

Response rate and participant characteristics

A total of 14,142 GPs were invited to complete the survey and $810(5.3 \%)$ responded.

Of these, 777 GPs completed the survey via the RCGP link and 33 using the social media link. Of these 777 respondents, 630 contained valid data (at least $27 \%$ of questions answered). 561 responders answered all the non-optional questions. Most responders were female (66\%), White ethnicity (78.6\%), GP partners (53.3\%), current members of RCGP (93.5\%) and worked 3-6 clinical sessions per week (55.5\%). Responses were recorded from GPs located across all regions and countries of the United Kingdom, with a reasonable balance between GPs working in cities, towns and rural settings (Table 1). Views about sit-stand desks

Most GPs (60.6\%) would like a sit-stand desk in their consultation room, while $35.0 \%$ agreed/somewhat agreed that they could be used for face-to-face consultations. Most GPs agreed sit-stand desks could be used for telephone consultations (91.9\%) and administrative tasks $(92.3 \%)$, but they were less certain about how acceptable they would be to patients within face to face consultations. $17.3 \%$ of GPs did not think that sit-stand desks would be acceptable to patients. Most GPs agreed/somewhat agreed that sit-stand desks would help start conversations with patients about the importance of reducing sitting time (79.8\%) and about increasing their physical activity for optimal health (71.2\%). See Figure 1.

GPs who already had a sit-stand desk

A total of 121 (19.2\%) GPs already had a sit-stand desk in their consultation room, and all but one of these GPs reported they used it at work, with most using it for telephone consultations and/or administration/meetings. Of these 121 responders, 44 (36\%) used their sit-stand desk for face-to-face consultations with patients.

Views about sit-stand desks according to demographic characteristics 
GPs aged 41-50 years were more likely to believe that sit-stand desks would be acceptable to patients, compared to younger GPs aged 24-40 years $(p=.04)$. Those aged 41 50 years also expressed more favourable views about the potential contribution that sit-stand desks could have on facilitating conversations with patients about their physical activity levels $(p=.02)$ and sitting time $(p=.03)$ compared to those aged $24-40$ years. Female GPs expressed more favourable views than their male counterparts about the potential contribution that sit-stand desks could have on facilitating conversations with patients about the importance of physical activity $(p=.02)$ and reducing sitting time $(p=>.01)$. GPs working four to six or seven to nine sessions per week were more positive about the potential use of sit-stand desks during face-to-face consultations ( $p=>.01)$, telephone consultations ( $p$ $=>.01)$ and for administrative tasks $(p=.02)$, compared to GPs working one to three sessions per week (Supplementary Table 1).

Views about sit-stand desks according to characteristics

There was no difference in GPs views about the potential use and impact of sit-stand desks between those who met the current physical activity guidelines and those who don't. GPs who currently use a sit-stand desks at work did think more favourably about their use during telephone consultations $(p=>.01)$ and for administrative tasks $(p=>0.01)$.

\section{Impact on the doctor-patient relationship}

A total of 271 GPs $(43 \%)$ reported being unsure of the impact that sit-stand desks would have on the doctor-patient relationship, with $26 \%$ expressing they thought that sitstand desks would somewhat negatively influence the relationship. GPs were largely unsure what impact sit-stand desks would have on their ability to concentrate at work (42.2\%), patients' perceptions of their listening skills (51.3\%), and patients' understanding of issues discussed in the consultation (68.6\%). However, only a small percentage of GPs thought sitstand desk would negatively impact their ability to concentrate (4.3\%), patients' perceptions 
of their listening skills $(8.4 \%)$, and patients' understanding of issues discussed in the consultation (4.0\%). Those aged $\geq 41$ years were more positive than those aged between 24 and 40 years about the potential impact that sit-stand desks would have on GPs concentration $(p=.03)$, patient's perception of GPs listening skills $(p=>.01)$ and patients' understanding of issues discussed in the consultation $(p=.02)$. See Supplementary Table 2.

Barriers to the implementation of sit-stand desks

Most GPs felt there was the potential for issues with doctor-patient communication from using a sit-stand desk in face-to-face consultations and this was thought to be the most likely barrier to successful implementation. About half (51.9\%) of GPs reported environmental or organisational (e.g., lack of financial resource and workload pressures) issues as potential barriers. Only $21.4 \%$ of GPs reported personal barriers (e.g., lack of time to stand or perception that it is uncomfortable to do so) as a potential issue to implementation. GPs health and sit-stand desks

Most GPs believed sit-stand desks would reduce their sitting time (94.6\%), increase their physical activity (89.8\%) and improve their posture/musculoskeletal health $(88.1 \%)$, wellbeing (79.0\%) and feelings of fatigue at the end of the working day (54.6\%) (Table 2). About two thirds of responders (62\%) met the World Health Organisations aerobic physical activity guidelines of achieving participation in at least 150 minutes of moderate intensity physical activity per week, while only $37 \%$ met the muscle strengthening guidelines of achieving $\geq 2$ days of muscle strengthening activity per week. When combined, only $29 \%$ of GPs met both guidelines. Most of the time at work was spent sitting (73\%), with $13 \%$ of sitting time spent in prolonged bouts of sitting ( $\geq 30$ minutes). Half of GPs reported having none or one break (such as standing up, stretching or taking a short walk) in sitting per hour. Themes from open text comments 
Of the 630 GPs to provide valid data, 212 left open text comments relating to the potential use of sit-stand desks within general practice. Key themes to emerge from these responses were cost (13 comments), potential impact on the doctor-patient relationship (9 positive comments and 34 negative comments), impact on health and wellbeing of GPs (26 positive comments and 3 negative comments), the impact on the energy and concentration of GPs (10 positive comments and 1 negative comment) and the potential positive influence on patients' health-related behaviours (6 comments).

\section{Discussion}

Summary

This study shows that the implementation of sit-stand desks within general practice would have support from GPs, who believe there would be benefits from doing so. The findings highlight that sit-stand desks were considered appropriate by GPs for most workrelated tasks, although there was not a clear consensus about whether they could be used during face-to-face patient consultations, with $43 \%$ of GPs unsure of the potential impact of the desks on the doctor-patient relationship. Most GPs thought that sit-stand desks would help start conversations with their patients about the importance of reducing their sitting time and participation in physical activity for maintaining good health. GPs reported sitting for about three quarters of their working day and few (29\%) reported participating in sufficient physical activity for optimal health.

\section{Strengths and limitations}

This study has several strengths, including a large sample size with responses from GPs working across all countries of the UK. To our knowledge this is the first study to investigate the views of GPs on the question of whether sit-stand desks should be implemented in general practice. This study also has some limitations. The response to the survey was modest ( $6 \%$ from the RCPG link) and those who responded may have held more 
favourable views than GPs who did not respond, although descriptive data shows that those who did respond varied according to gender, ethnicity, BMI and region of the UK, providing some reassurance the findings represent a broad range of GPs. The cross-sectional nature of findings may limit the wider applicability of sit-stand desks by GPs, however, our findings can be used to inform the design of future research endeavours on this question and the working practices of GPs. It is also important to note that working hours only form a part of a GPs day, therefore time outside this (i.e., leisure time) and levels of physical activity and sedentary behaviour during this time should be examined in future research.

Comparison with existing literature

Although this study is the first to investigate GPs views about the use of sit-stand desks during their working day, our findings are consistent with evidence showing that sitstand desks are widely acceptable in office workers $(13,21,22)$. Given previous evidence suggests that secondary care patients' views of their doctor can vary depending on whether they are sitting or standing delivering care/consultations as part of hospital inpatient stays (23), it is equally important that patients' views about their GP a using sit-stand desk during face-to-face consultations is explored in future research. Such research may help to identify strategies to mitigate any potential negative impact on the patient consultation experience and guide future policy.

\section{Implications for research and/or practice}

This study has highlighted that there is a willingness by GPs to use sit-stand desks within patient consultations, and for other work tasks. However, it would be premature to proceed with a widescale implementation of sit-stand desks in general practice before evidence about their impact on the working day and health of GPs is known. Data on the views and experiences of patients from participating in GP standing consultations is also imperative. Within future research studies it would also be important to assess whether 
standing consultations lead to GPs and patients sitting less and being more physically active. As highlighted earlier, the findings regarding the use of sit-stand desks during face-to-face consultations was mixed. Future research should consider investigating this specific question in more detail to explore what the concerns might be that are driving this concern in some GPs. There are already strategies in primary care that are designed to promote physical activity in patients, such as the Active Practice Charter and sit-stand desks could be couched within such campaigns, as a further method of promoting physical activity with patients.

In conclusion, GPs in the UK generally supported the implementation of sit-stand desks within general practice. Future use of sit-stand desks during face-to-face consultations should be carefully managed, with consideration given to the potential impact on the doctorpatient relationship. Any future research involving sit-stand desk interventions with GPs should focus on understanding the views of patients and whether such a change to their consultations with the GP is acceptable.

\section{Supplementary data}

Supplementary table 1. Differences between age group, gender and number of sessions worked and GPs views on the potential use of sit-stand desks within primary care.

Supplementary table 2. Differences between age group, gender and number of sessions worked and GPs views on the potential impact of using sit-stand desks during face-to-face consultations with able-bodied adult patients.

Supplementary table 3. Differences between age group, gender and number of sessions worked and GPs views on the potential impact of using sit-stand desks during telephone consultations. 


\section{Additional information}

Funding

AD is supported by a National Institute for Health Research (NIHR) Research Professorship award. CE and SC are supported by the NIHR Leicester Biomedical Research Centre -

Lifestyle theme. The views expressed are those of the author(s) and not necessarily those of the NHS, the NIHR or the Department of Health and Social Care.

\section{Ethical approval}

Ethical approval was granted by Loughborough University Human Participants Sub-

Committee (reference number 1498). All participants provided informed consent.

Competing interests

The authors declare that there are no conflicts of interest.

\section{Acknowledgements}

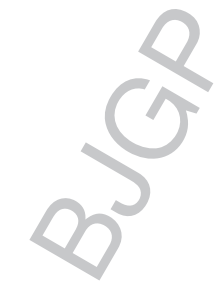

The authors would like to thank all the GPs who completed the study questionnaire. Also, our thanks go to the RCGP who facilitated and organised data collection processes. 


\section{References}

1. van Uffelen JG, Wong J, Chau JY, et al. Occupational sitting and health risks: a systematic review. Am J Prev Med. 2010;39(4):379-388. DOI: 10.1016/j.amepre.2010.05.024

2. Hallman DM, Gupta N, Mathiassen SE, et al. Association between objectively measured sitting time and neck-shoulder pain among blue-collar workers. Int Arch Occup Env Heal. 2015;88(8):1031-1042. DOI: 10.1007/s00420-015-1031-4

3. Zhai L, Zhang Y, Zhang D. Sedentary behaviour and the risk of depression: a metaanalysis. Br J Sport Med. 2015;49:705-709. DOI: 10.1136/bjsports-2014-093613

4. Teychenne M, Costigan SA, Parker K. The association between sedentary behaviour and risk of anxiety: a systematic review. BMC Pub Heal. 2015; 15:513. DOI:

$10.1186 / \mathrm{s} 12889-015-1843-\mathrm{x}$

5. Boberska M, Szczuka Z, Kruk M, et al. Sedentary behaviors and health-related quality of life. A systematic review and meta-analysis. Health Psychol Rev. 2017;1-55. DOI:

$10.1080 / 17437199.2017 .1396191$

6. Clemes SA, O’Connell SE, Edwardson CL. Office workers' objectively measured sedentary behavior and physical activity during and outside working hours. J Occup Environ Med. 2014;56(3):298-303. DOI: 10.1097/JOM.0000000000000101

7. Healy GN, Eakin EG, Lamontagne AD, et al. Reducing sitting time in office workers: short-term efficacy of a multicomponent intervention. Prev Med. 2013;57(1):43-48. DOI:

10.1016/j.ypmed.2013.04.004 
8. Benatti FB, Ried-Larsen M. The Effects of Breaking up Prolonged Sitting Time: A Review of Experimental Studies. Med Sci Sport Exerc. 2015;47(10):2053-2061. DOI: 10.1249/MSS.0000000000000654

9. Loh R, Stamatakis E, Folkerts D, et al. Effects of Interrupting Prolonged Sitting with Physical Activity Breaks on Blood Glucose, Insulin and Triacylglycerol Measures: A Systematic Review and Meta-analysis. Sport Med. 2020;50(2):295-330. DOI: 10.1007/s40279-019-01183-w

10. Dempsey PC, Owen N, Yates TE, et al. Sitting Less and Moving More: Improved Glycaemic Control for Type 2 Diabetes Prevention and Management. Curr Diab Rep. 2016;16(11):114. DOI: 10.1007/s11892-016-0797-4

11. Thorp AA, Kingwell BA, Owen N, et al. Breaking up workplace sitting time with intermittent standing bouts improves fatigue and musculoskeletal discomfort in overweight/obese office workers. Occup Environ Med. 2014;71(11):765-771. DOI: 10.1136/oemed-2014-102348

12. Bergouignan A, Legget KT, De Jong N, et al. Effect of frequent interruptions of prolonged sitting on self-perceived levels of energy, mood, food cravings and cognitive function. Int J Behav Nutr Phys Act. 2016;13(1):113. DOI: 10.1186/s12966-016-0437-z

13. Edwardson CL, Yates T, Biddle SJH, et al. Effectiveness of the Stand More AT (SMArT) Work intervention: cluster randomised controlled trial. BMJ. 2018;363. DOI: 10.1136/bmj.k3870

14. Guthold R, Stevens GA, Riley LM, et al. Worldwide trends in insufficient physical activity from 2001 to 2016: a pooled analysis of 358 population-based surveys with 1.9 million participants. Lancet Glob Heal. 2018;6(10):1077-1086. DOI: 10.1016/S2214$109 \times(18) 30357-7$ 
15. Chatterjee R, Chapman T, Brannan MG, et al. GPs' knowledge, use, and confidence in national physical activity and health guidelines and tools: a questionnaire-based survey of general practice in England. Br J Gen Pract. 2017;67(663):668-675. DOI:

10.3399/bjgp17X692513

16. Rashid MA. Consultations in primary care should be held standing up. BMJ (Online). 2014;348. DOI: 10.1136/bmj.g1558

17. Quiles NN, McCullough AK, Piao L. Validity and Reliability of the Exercise Vital Sign Questionnaire in an Ethnically Diverse Group: A Pilot Study. J Prim Care Com Heal. 2019. DOI: $10.1177 / 2150132719844062$

18. Hansen V, Girgis A. Can a single question effectively screen for burnout in Australian cancer care workers? BMC Health Serv Res. 2010;10:341. DOI: 10.1186/1472-6963-10-341

19. Kuorinka I, Jonsson B, Kilbom A, et al. Standardised Nordic questionnaires for the analysis of musculoskeletal symptoms. Appl Ergon. 1987;18(3):233-237. DOI: 10.1016/0003-6870(87)90010-x

20. Ng Fat L, Scholes S, Boniface S, et al. Evaluating and establishing national norms for mental wellbeing using the short Warwick-Edinburgh Mental Well-being Scale (SWEMWBS): findings from the Health Survey for England. Qual Life Res. 2017;26(5)1129-1144. DOI: 10.1007/s11136-016-1454-8

21. Grunseit AC, Chau JYY, Van Der Ploeg HP, et al. "thinking on your feet": A qualitative evaluation of sit-stand desks in an Australian workplace. BMC Pub Heal. 2013;13:365. DOI: $10.1186 / 1471-2458-13-365$ 
22. Healy G, Alkhajah T, Winkler E, et al. Reducing sitting time in office workers:

Efficacy and acceptability of sit-stand workstations. J Sci Med Sport. 2012;15(1):196.

DOI:10.1016/j.jsams.2012.11.480

23. Swayden KJ, Anderson KK, Connelly LM, et al. Effect of sitting vs, standing on perception of provider time at bedside: A pilot study. Patient Educ Couns. 2012;86(2):166-

171. DOI: 10.1016/j.pec.2011.05.024 
Tables and figures

Table 1. Participant characteristics (data represent the sample size, $n$, and the proportions, \%)

\begin{tabular}{|c|c|}
\hline Characteristic & $n=630$ \\
\hline \multicolumn{2}{|l|}{ Age } \\
\hline $24-40$ years & $155(26.1)$ \\
\hline $41-50$ years & $237(39.9)$ \\
\hline $51-70$ years & $202(34.0)$ \\
\hline \multicolumn{2}{|l|}{ Gender } \\
\hline Male & $197(33.2)$ \\
\hline Female & $392(66.0)$ \\
\hline In another way/ Prefer not to say & $5(0.8)$ \\
\hline \multicolumn{2}{|l|}{ Ethnicity } \\
\hline White & $467(78.6)$ \\
\hline Other & $127(21.4)$ \\
\hline \multicolumn{2}{|l|}{ GP working region } \\
\hline North East England & $15(2.5)$ \\
\hline North West England & $61(10.3)$ \\
\hline Yorkshire and The Humber & $43(7.2)$ \\
\hline West Midlands & $62(10.4)$ \\
\hline East Midlands & $42(7.1)$ \\
\hline East of England & $53(8.9)$ \\
\hline South West & $86(14.5)$ \\
\hline South East & $65(10.9)$ \\
\hline Greater London & $59(9.9)$ \\
\hline Wales & $30(5.1)$ \\
\hline Scotland & $65(10.9)$ \\
\hline Northern Ireland & $13(2.2)$ \\
\hline \multicolumn{2}{|l|}{ GP working location } \\
\hline City & $197(33.3)$ \\
\hline Town & $294(49.7)$ \\
\hline Rural & $100(16.9)$ \\
\hline \multicolumn{2}{|l|}{ Job role } \\
\hline Managing/executive partner & $22(3.7)$ \\
\hline GP partner & $315(53.3)$ \\
\hline Salaried GP & $160(27.1)$ \\
\hline Locum GP & $59(10.0)$ \\
\hline GP specialist & $35(5.9)$ \\
\hline \multicolumn{2}{|l|}{ Sessions of work per week } \\
\hline $1-3$ & $65(11.0)$ \\
\hline $3-6$ & $328(55.5)$ \\
\hline 7 or more & $198(33.5)$ \\
\hline \multicolumn{2}{|l|}{ RCGP active practice charter } \\
\hline Yes & $29(4.9)$ \\
\hline No $<$ & $261(44.3)$ \\
\hline Don't know & $299(50.8)$ \\
\hline
\end{tabular}


Standing desks could be used during GP face-to-face consultations with able bodied adults also standing

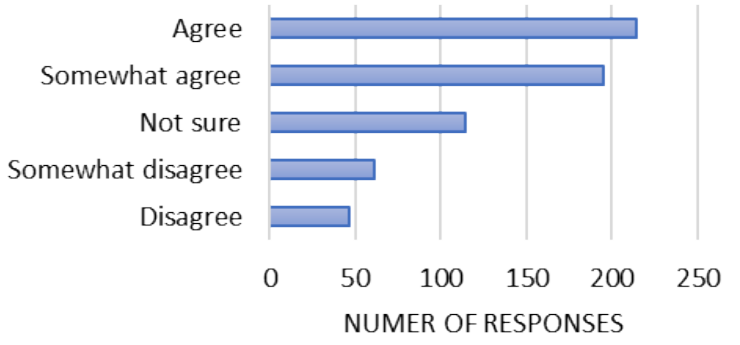

Standing desks could be used for administrative duties or tasks by GPs

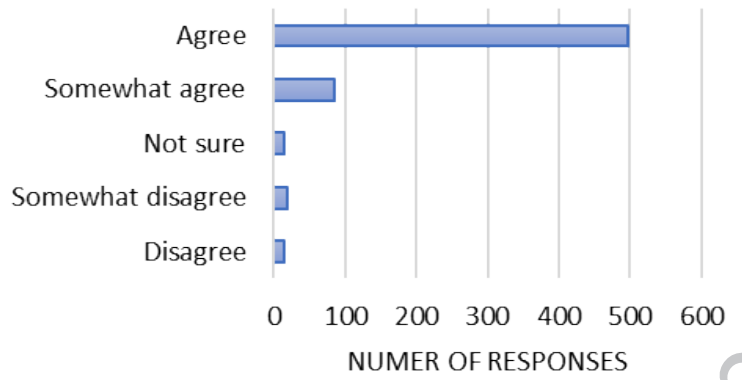

Standing desks during GP consultations will help start conversations with patients about the importance of physical activity to improve health

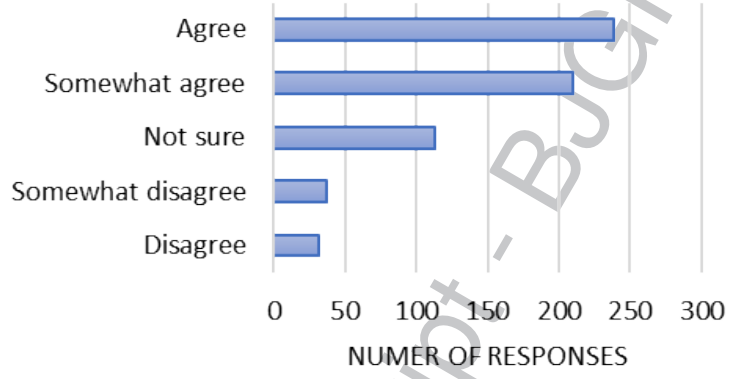

Standing desks could be used during GP telephone consultations with adults

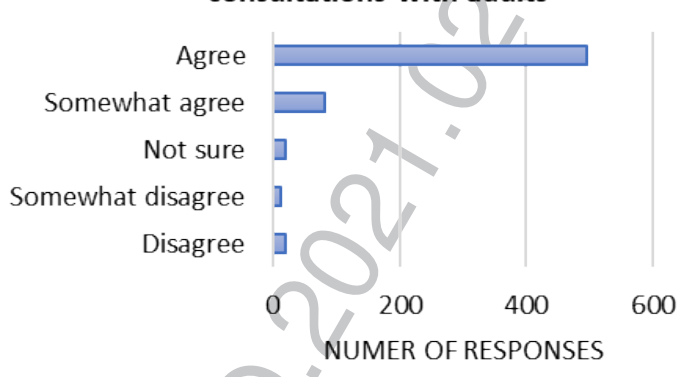

The use of standing desks by GPs is likely to be acceptable to patients able to stand

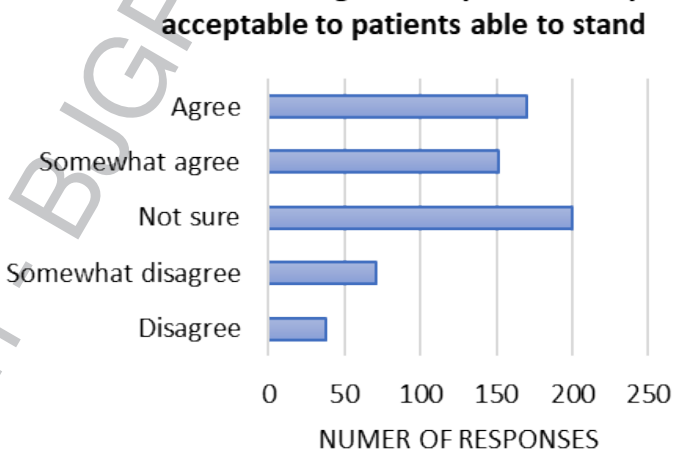

Standing desks during GP consultations will help start conversations with patients about the importance of reducing sitting time to improve health

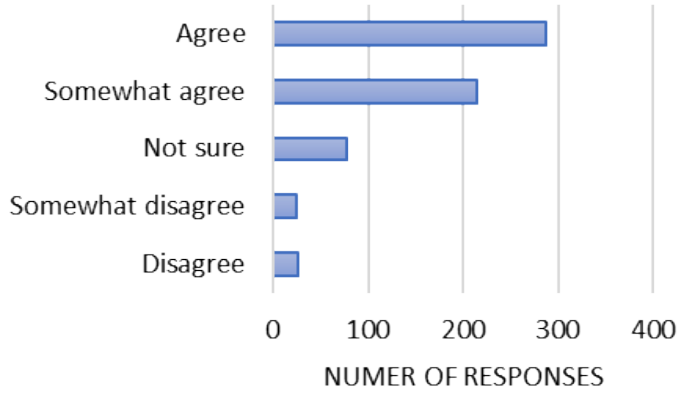

Figure 1. GPs views of the potential use of sit-stand desks. 


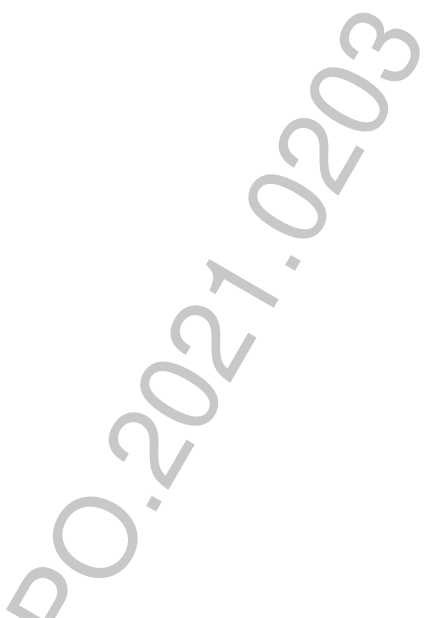

Table 2. GPs views of the potential impact of sit-stand desks on their physical behaviour, health and wellbeing.

\begin{tabular}{|c|c|c|c|c|}
\hline & & $\begin{array}{c}\text { Face-to-face consultation } \\
(\mathrm{n}[\%])\end{array}$ & $\begin{array}{c}\text { Task } \\
\begin{array}{c}\text { Telephone consultation } \\
(\mathrm{n}[\%])\end{array} \\
\end{array}$ & $\begin{array}{c}\text { Administration } \\
\text { (n [\%]) }\end{array}$ \\
\hline \multirow{3}{*}{ Sitting time } & Negatively/somewhat negatively & $17[2.7]$ & $19[3.0]$ & $23[3.7]$ \\
\hline & Unsure & $47[7.5]$ & $19[3.0]$ & $23[3.7]$ \\
\hline & Positively/somewhat positively & $566[89.8]$ & $593[93.9]$ & 584 [92.7] \\
\hline \multirow{3}{*}{ Physical activity } & Negatively somewhat negatively & $23[3.7]$ & $14[2.2]$ & $16[2.6]$ \\
\hline & Unsure & $52[8.3]$ & $37[5.9]$ & $45[7.1]$ \\
\hline & Positively/somewhat positively & $566[2.7]$ & 579 [91.9] & $569[90.3]$ \\
\hline \multirow{3}{*}{ Posture } & Negatively/somewhat negatively & $23[3.7]$ & $25[4.0]$ & $29[4.6]$ \\
\hline & Unsure & $52[8.3]$ & $48[7.6]$ & $50[7.9]$ \\
\hline & Positively/somewhat positively & $555[88.1]$ & $557[88.5]$ & $551[87.5]$ \\
\hline \multirow{3}{*}{$\begin{array}{l}\text { Musculoskeletal } \\
\text { health }\end{array}$} & Negatively somewhat negatively & $23[3.6]$ & $21[3.4]$ & $28[4.4]$ \\
\hline & Unsure & $52[8.3]$ & $51[8.1]$ & $50[7.9]$ \\
\hline & Positively/somewhat positively & 555 [88.1] & $558[88.6]$ & $552[87.7]$ \\
\hline \multirow{3}{*}{ Wellbeing } & Negatively somewhat negatively & $25[3.9]$ & $29[4.6]$ & $32[5.1]$ \\
\hline & Unsure & $107[17.0]$ & $84[13.3]$ & $90[14.3]$ \\
\hline & Positively/somewhat positively & $498[79.0]$ & $517[82.1]$ & $508[80.6]$ \\
\hline \multirow{3}{*}{$\begin{array}{l}\text { Fatigue at the end } \\
\text { of the day }\end{array}$} & Negatively/somewhat negatively & $90[14.3]$ & $83[13.1]$ & $81[12.8]$ \\
\hline & Unsure & $196[31.1]$ & $175[27.8]$ & $176[27.9]$ \\
\hline & Positively/somewhat positively & $344[54.6]$ & $372[59.0]$ & $373[59.2]$ \\
\hline
\end{tabular}



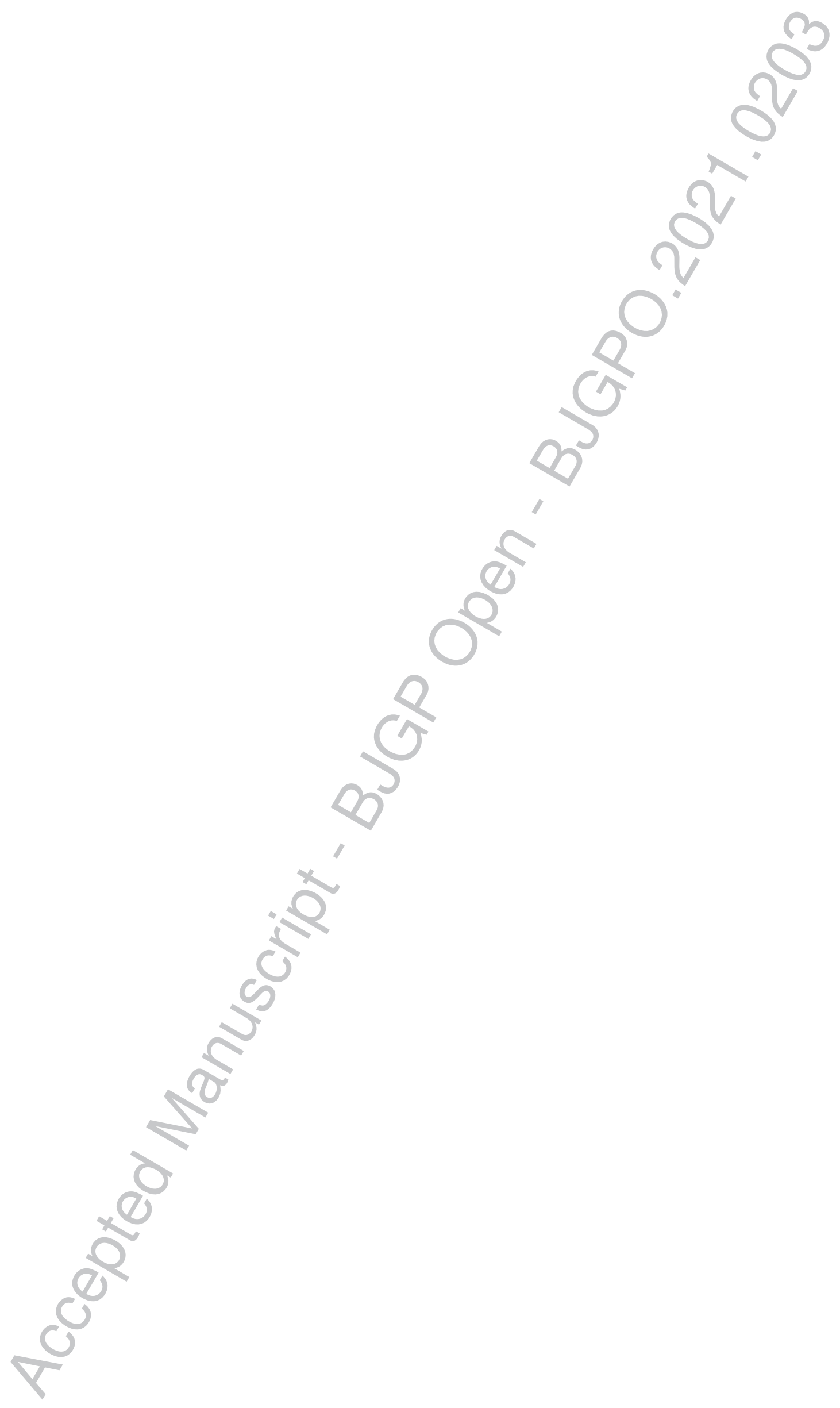